\title{
Crude Extracts of Mitracarpus scaber Roots Significantly Ameliorate Paracetamol (PCM)-Induced Liver Damage in Rats
}

\author{
Okonkwo Francis Obiora ${ }^{1}$, Jonathan Bege ${ }^{1, ~}$, Ibibra Joel Agat ${ }^{1}$, Nvau John Barnabas ${ }^{2}$ \\ ${ }^{1}$ Department of Biochemistry, Faculty of Natural and Applied Sciences, Plateau State University, Bokkos, Nigeria \\ ${ }^{2}$ Department of Chemistry, Faculty of Natural and Applied Scinces, Plateau State University, Bokkos, Nigeria
}

Email address:

obioraokonkwo@gmail.com (O. F. Obiora), begejonathan@gmail.com (J. Bege), joelibibra@gmail.com (I. J. Agat),

johmnvau5@gmail.com (N. J. Barnabas)

${ }^{*}$ Corresponding author

\section{To cite this article:}

Okonkwo Francis Obiora, Jonathan Bege, Ibibra Joel Agat, Nvau John Barnabas. Crude Extracts of Mitracarpus scaber Roots Significantly Ameliorate Paracetamol (PCM)-Induced Liver Damage in Rats. American Journal of Biomedical and Life Sciences.

Vol. 7, No. 6, 2019, pp. 148-154. doi: 10.11648/j.ajbls.20190706.14

Received: October 16, 2019; Accepted: October 8, 2019; Published: November 27, 2019

\begin{abstract}
Traditional medicine has received considerable acceptance in recent years, especially in Africa probably due to perceived efficacy and the fact that they are a cheap source of medicine. It can also be attributed to the pharmacological properties of plants, including antioxidant and hepatoprotective properties. The hepatoprotective effects of aqueous extract and $10 \%$ ethanolic extract of the roots of Mitracarpus scaber against paracetamol (PCM)-induced hepatotoxicity in Wistar rats of both sexes were investigated. Liver damage was induced by oral administration of $1.5 \mathrm{mg} / \mathrm{kg}$ bodyweight of PCM. After pretreatment for 6 days with aqueous and ethanolic extract of Mitracarpus scaber root (200 and 500 $\mathrm{mg} / \mathrm{kg}$ ), hepatoprotective properties of the plant was evaluated by estimating the activities of alanine aminotransferase (ALT), aspartate aminotransferase (AST), and alkaline phosphatase (ALP), followed by histopathology, as compared with the control group (group induced with liver damage but not treated). Administration of the extracts showed significant $(\mathrm{p}<0.05)$ and dose-dependent hepatoprotective activity resulting in decrease in the activity of ALT and AST. These data revealed that the roots of Mitracarpus scaber aqueous and ethanolic extracts possess significant hepatoprotective activity against PCM-induced toxicity attributable to its constituent phytochemicals. The mechanism of hepatoprotection seems to be through the modulation of antioxidant enzyme systems.
\end{abstract}

Keywords: Mitracarpus scaber, Roots, Paracetamol, Hepatoprotection, Medicinal Plants

\section{Introduction}

The liver is a vital organ in the body that performs several metabolic functions such as metabolism of macromolecules and all the biochemical pathways to growth, provision of energy, reproduction, nutrient supply, fighting against diseases, regulation of homeostasis of metabolism, elimination and detoxification of metabolites or xenobiotics generated due to exposure to drugs in the body [1, 2]. Prior to the diverse functions of the liver, the liver is vulnerable to injuries that can be caused by hepatotoxins, free radicals, and other reactive oxygen species (ROS), drugs, and viral infiltration through ingestion or infection [3, 4]. Injuries to the liver can also be caused by xenobiotics, alcohol consumption, malnutrition, infection, anaemia and medications [5]. Almost all kinds of liver damages can be induced by the reaction of hepatotoxic compounds with basic cellular components. Harmful substances absorbed from the small intestine, move first, to the liver which may lead to certain liver diseases. Thus liver diseases are one of the major health problems, hence hepatoprotective agents are developed to reduce ROS production and agents that can also scavenge free radicals, which serve as causes of liver injuries and diseases. Chemical toxins (including acetaminophen, carbon tetrachloride, galactosamine, and thioacetamide) are often used as the model substances causing experimental hepatocyte injury in both in vivo and in vitro conditions [6].

Paracetamol is widely used as an analgesic and to also 
reduce fever. However, it can lead to acute liver necrosis when in high doses. In the United States alone, it accounts for more than $50 \%$ of overdose-related acute liver failure and about $20 \%$ of the liver transplant cases [7,8]. Metabolism of paracetamol takes place mainly in the liver, whereby it is metabolized to glucuronide and sulphate conjugates that are subsequently excreted. Paracetamol toxicity has been attributed to the formation of $N$-acetyl $p$-benzoquinone imine (NAPQI), a highly reactive metabolite, by the hepatic cytochrome P450. NAPQI is initially detoxified by conjugation with reduced glutathione (GSH) to form mercapturic acid. However, when the rate of NAPQI formation exceeds the rate of detoxification by GSH, it oxidizes tissue macromolecules such as lipids or thio (-SH) group of protein and alters the homeostasis of calcium after depleting GSH $[8,9]$, causing damage to the macromolecules in vital biomembranes and liver injury [10].

The use of synthetic drugs to cure liver injuries is becoming limited due to the fact that these drugs are sometimes inadequate and can result in serious adverse effects. Moreover, there are still no specific treatments in modern medicine that give protection to the liver against damage or help to regenerate hepatic cells [11]. Recently, the use of medicinal plants to cure various forms of liver diseases and dysfunctions is becoming increasingly popular and has received wide acceptance [12], hence the use of herbal preparations in traditional medicine is becoming an alternative and can also serve as a replacement to synthetic drugs of doubtful efficacy and safety.

Medicinal plants are considered as one of the richest bioresource of drugs used in traditional systems of medicine, modern medicines, nutraceuticals, food supplements, folk medicines, pharmaceutical intermediates and chemical entities for synthetic drugs [13]. According to WHO, over $70 \%$ of the world populations rely on medicinal plants for primary healthcare [14].

Despite the achievements in technology, Africa, and other parts of the world (especially developing countries), use plants in form of decoction, crude extract, infusion tincture, and sometimes rubbed on the skin in order to treat certain diseases [15]. Traditional medicine has been widely accepted in Africa because of the unwanted side effects and high cost associated with synthetic drugs, hence researchers developed interest in some of the medicinal plants in order to check for plants having hepatoprotective properties so as to improve the treatment of liver disorders.

Amongst the myriad of therapeutic plant species, $M$. scaber is among the species applied in the treatment of various ailments [16]. The plant family, Rubiaceae, popularly known as Madder family belongs to the Gentianales order, recently called Rubiales order. The family consists of about 500 genera and 6,000 species distributed all over the world with some of them being tropical trees and shrubs (erect, struggling or twining) while few members are herbs (erect or decumbent) [17]. Mitracarpus scaber is a perennial annual herb of about $30 \mathrm{~cm}$ tall or much smaller and possess rough leaves. The aerial parts and the leaves of the plants are mostly used. In Nigeria, it is known as Obuobwa in Igbo language, Gududal in Hausa language, Irawo lle in Yoruba language, and Arechek in Rukuba language, a tribe in Jos Plateau State, Nigeria. The leaves of M. scaber have been widely used in West Africa for the treatment of headaches, toothaches, amenorrhea, dyspepsia, hepatic diseases, skin infections, venereal diseases, as well as leprosy $[18,19]$. Leaf extracts of Mitracarpus scaber have shown antimicrobial, antitrypanosomal, hepatoprotective, and anti-inflammatory effects [19, 20]. It is claimed that the plant has both antibacterial and antifungal activities. In some parts of eastern Nigeria, it is claimed that the roots of the plant have the potential for treating liver diseases whereby the roots are boiled inside palm wine and it is taken orally.

Although several studies have been carried out on Mitracarpus Scaber, the studies, however, did not discuss much on the roots of this plant. Therefore, the purpose of this study was to assess hepatoprotective properties of crude $10 \%$ ethanolic and aqueous roots extracts of Mitracarpus scaber, in order to ensure its proper use, ascertain veracity of the claims, and also help in the improvement of public health.

\section{Materials and Methods}

\subsection{Collection of Plant Material}

The roots of Mitracarpus scaber were collected from the Plateau State University, Bokkos, environment. The collected samples were washed thoroughly in running tap water and were dried in a shade away from direct sunshine. The dried samples were crushed using mortar and pestle. The fine powder was obtained by sieving. After weighing, the powder was packed in clean labeled bottles and stored until use.

\subsection{Preparation of Aqueous Extract}

Extraction was performed by macerating air-dried, powdered roots of $M$. Scaber $(60 \mathrm{~g})$ soaked in distilled water $(600 \mathrm{ml})$ at room temperature for $72 \mathrm{hrs}$, and was occasionally shaken. The crude aqueous extract was filtered using Whatman NO. 1 filter paper and was concentrated in a water bath at $70^{\circ} \mathrm{C}$ to obtain concentrated extract and was allowed to air dry in a beaker. The dry residue was stored at $4^{\circ} \mathrm{C}$, and at the time of use, was re-suspended in distilled water.

\subsection{Preparation of Ethanolic Extract}

Extraction was performed by macerating air-dried, powdered M. Scaber $(60 \mathrm{~g})$ soaked in $10 \%$ ethanol $(600 \mathrm{ml})$ at room temperature for $24 \mathrm{hrs}$, and was occasionally shaken. The crude $10 \%$ ethanolic extract was filtered using, Whatman NO. 1 filter paper, concentrated using a water bath at $78^{\circ} \mathrm{C}$ to remove the ethanol and to obtain concentrated extract and was allowed to air dry in a beaker. The dry residue was stored at $4^{\circ} \mathrm{C}$, and at the time of use, was re-suspended in distilled water. 


\subsection{Preparation of Stock Plant Extract Solutions}

Preparation of the solution was done by dissolving four (4) grams of the powdered extract in ten milliliters of distilled water to give a solution of concentration $400 \mathrm{mg} / \mathrm{ml}$ of $M$.
Scaber roots aqueous and ethanolic extracts. The stock solution was prepared for administering to the rats. The volumes of the extract administered to the animals were calculated using the formula by Gosh (1984) as shown below:

$$
\text { Volume given to each animal }(\mathrm{ml})=\frac{\text { body weight of animal }(\mathrm{kg}) \mathrm{X} \text { dose }\left(\frac{\mathrm{mg}}{\mathrm{kg}}\right)}{\text { Concentration of extract }\left(\frac{\mathrm{mg}}{\mathrm{ml}}\right)}
$$

\subsection{Experimental Animals}

Wistar rats weighing between 100 to $150 \mathrm{~g}$ were purchased from the Animal House of the National Veterinary Research Institute (NVRI) Vom. The animals were kept in metal cages in a well-ventilated room and allowed to acclimatize for 14 days. The animals were fed with standard pelleted rat feed from Dagwom farm mill, NVRI Vom, with drinking water provided ad libitum. All experiments were conducted in accordance with the principles and guidelines for the care and use of laboratory animals. (NRC, 1996) and approved by the animals' welfare and ethics committee of the NVRI Vom.

\subsection{Experimental Design}

A total of 24 rats were used. The rats were randomly divided, into six groups of four rats each and treated orally as follows for 4 days 24-h after the induction of liver damage:

Group A: Normal control, received normal saline orally.

Group B: Paracetamol control, administered with paracetamol $1500 \mathrm{mg} / \mathrm{kg}$ body wt. in distilled water.

Group C: Paracetamol as in group B $+200 \mathrm{mg} / \mathrm{kg}$ b. wt. of the aqueous root extract of Mitracarpus scaber.

Group D: Paracetamol as in group B $+500 \mathrm{mg} / \mathrm{kg}$ b. wt. of the aqueous root extract of Mitracarpus scaber.

Group E: Paracetamol as in group B $+200 \mathrm{mg} / \mathrm{kg}$ b. wt. of the $10 \%$ ethanolic root extract of Mitracarpus scaber.

Group F: Paracetamol as in group B $+500 \mathrm{mg} / \mathrm{kg}$ b. wt. of the $10 \%$ ethanolic root extract of Mitracarpus scaber.

On the sixth day, all the animals were sacrificed under chloroform anaesthesia and blood and liver samples were collected.

\subsection{Biochemical Analysis}

The blood collected was allowed to clot for 30 minutes and centrifuged at $3000 \mathrm{rpm}$ (revolution per minute) for 5 minutes to obtain serum. The supernatant was collected using Pasteur pipette into sample bottles. The serum was used for biochemical estimations of some liver enzymes; alanine aminotransferase (ALT), aspartate aminotransferase (AST), and alkaline phosphatase (ALP). The activities of serum transaminases (ALT and AST), were assayed using the methods of Reitman and Frankel [21]. Serum alkaline phosphatase activity was determined using the method of King and Armstrong [22].

\subsection{Histological Studies}

Histological examination was carried out according to the methods of Avwioro [23]. The livers and kidneys of rats selected at random from each group were harvested and fixed in $10 \%$ formol saline for 3 days. After the fixation, all tissue from the organs collected were cut into thin slices of $5 \mathrm{~mm} \times$ $2 \mathrm{~mm} \times 1 \mathrm{~mm}$ thick and was processed in an automated tissue machine; The SPIN tissue processor, STP 120 (Thermo scientific): to undergo dehydration, clearing, and impregnation for 22 hours. The tissues were embedded in molten paraffin wax, using embedding molds. The tissues were embedded using embedding cassettes on a tissue Tek Embedding Centre (SLEE MPS/P2), and cooled rapidly on the cooling component and were sectioned using a rotary microtome (MICROM HM340E Thermo Scientific)) set at 4 microns, picked on well-labelled slides and stained with haemotoxylin and eosin ( $\mathrm{H}$ and $\mathrm{E})$ stain. Sections were then placed in slide carriers and placed in a $40^{\circ} \mathrm{C}$ oven to dry overnight. The slides were then observed and analyzed under the light microscope with magnification of X100 and X400 (oil immersion) and their photomicrographs were taken. The purpose of the histology section is to observe for any sign of histopathological changes in the organs.

\subsection{Statistical Analysis}

Data were expressed in mean \pm S. E. Liver function parameters were compared against the animals respective vehicle groups using one-way analysis of variants (ANOVA) and LSD post hoc test with SPSS version 20. Values of $\mathrm{p}<0.05$ were considered statistically significant.

Histopathological data were analyzed by a registered and practicing veterinary pathologist. All significant changes detected, after the histopathology, were used to indicate toxicity to either the liver or kidney.

\section{Results and Analyses}

\subsection{Biochemical Parameters}

The hepatic enzymes (AST, ALT, and ALP) in serum significantly $(P \leq 0.05)$ increased in $\mathrm{PCM}$-control group $(56.66 \pm 1.56 \mathrm{U} / \mathrm{L}, 21.00 \pm 1.56 \mathrm{U} / \mathrm{L}$ and $48.75 \pm 0.91 \mathrm{U} / \mathrm{L})$ respectively when compared to normal control group $(51.32 \pm 0.87 \mathrm{U} / \mathrm{L}, 16.00 \pm 1.08 \mathrm{U} / \mathrm{L}$ and $44.91 \pm 1.18 \mathrm{U} / \mathrm{L})$ respectively. The aqueous extract of Mitracarpus Scaber roots treatment with $(200 \mathrm{mg} / \mathrm{kg})$ showed increased levels of AST, ALT and ALP $(56.66 \pm 1.56 \mathrm{U} / \mathrm{L}, 21.00 \pm 1.56 \mathrm{U} / \mathrm{L}$ and $48.75 \pm 0.91 \mathrm{U} / \mathrm{L})$ respectively when compared to paracetamol-treated animals. However, the group treated with $(500 \mathrm{mg} / \mathrm{kg})$ of the aqueous extract, showed decrease in the levels of AST and ALT (37.24 $\pm 0.27 \mathrm{U} / \mathrm{L}$ and $15.25 \pm 0.63$ $\mathrm{U} / \mathrm{L}$ ) respectively as compared with the (PCM-control) 
except in the levels of ALP which was increased significantly (from $48.75 \pm 0.91 \mathrm{U} / \mathrm{L}$ to $66.37 \pm 0.73 \mathrm{U} / \mathrm{L}$ ) as shown in Figure 1.

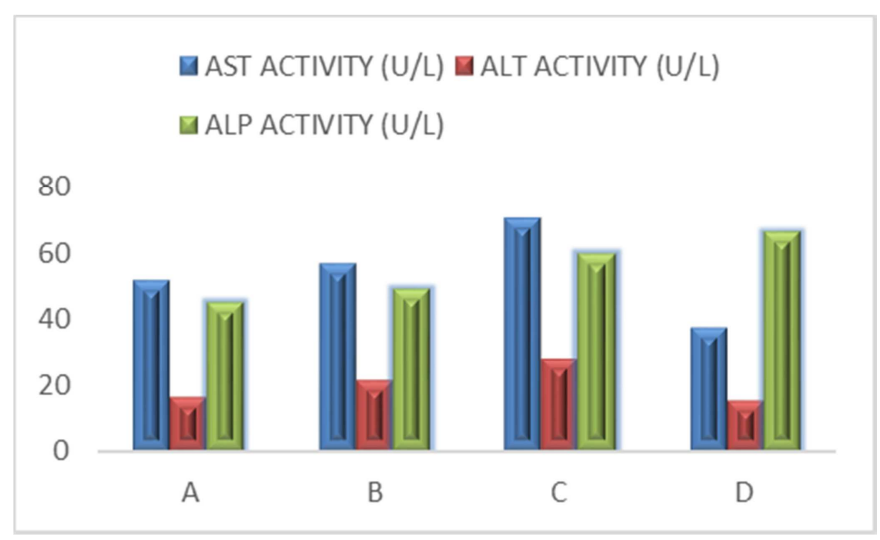

Figure 1. Effect of aqueous crude extracts of M. Scaber roots on alanine aminotransferase $(A L T)$, aspartate aminotransferase (AST), and alkaline phosphatase (ALP) activities in paracetamol (PCM)-induced liver damage Wister rats.

$10 \%$ ethanol extract of Mitracarpus Scaber roots treatment with $(200 \mathrm{mg} / \mathrm{kg})$ showed decreased AST and ALT levels $(45.96 \pm 1.74$ and $15.75 \pm 1.89 \mathrm{U} / \mathrm{L})$ respectively, while ALP level was slightly increased $(50.29 \pm 1.70 \mathrm{U} / \mathrm{L})$ when compared to paracetamol-control group $(\mathrm{AST}=56.66 \pm 1.56$ $\mathrm{U} / \mathrm{L}, \quad \mathrm{ALT}=21.00 \pm 1.47 \mathrm{U} / \mathrm{L}$ and $\mathrm{ALP}=48.75 \pm 0.91 \mathrm{U} / \mathrm{L})$ respectively. However, the group treated with $(500 \mathrm{mg} / \mathrm{kg})$ of the ethanol extract, showed an increase in the levels of AST and ALT (from $56.66 \pm 1.56 \mathrm{U} / \mathrm{L}$ to $65.55 \pm 2.05 \mathrm{U} / \mathrm{L}$ and $21.00 \pm 1.47 \mathrm{U} / \mathrm{L}$ to $32.25 \pm 1.84 \mathrm{U} / \mathrm{L})$ with ALP levels significantly elevated (from $48.75 \pm 0.91 \mathrm{U} / \mathrm{L}$ to $115.24 \pm 6.69$ $\mathrm{U} / \mathrm{L}$ ) when compared with the induction control as shown in Figure 2.

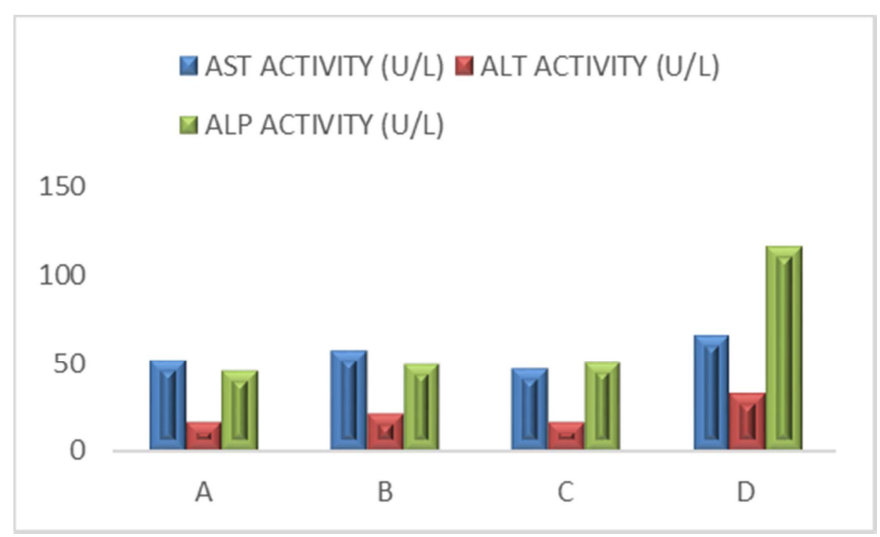

Figure 2. Effect of $10 \%$ ethanolic crude extracts of $M$. Scaber roots on alanine aminotransferase (ALT), aspartate aminotransferase (AST), and alkaline phosphatase (ALP) activities in paracetamol (PCM)-induced liver damage Wister rats.

\subsection{Histopathology of the Liver and Kidney}

The results for histopathology is as shown in the plates below:
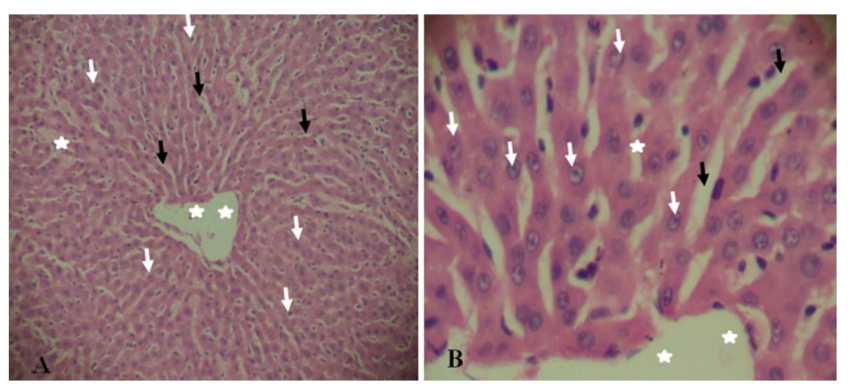

Figure 3. Liver of albino rat not induced + normal saline showing normal tissue architecture evident by the hepatocytes presenting with intact nuclei (white arrows) surrounded by intact cytoplasm and interspersed by hepatic sinusoids (black arrows) which are linked with the central vein (white stars). $H \& E$ A: X100 B: X400.
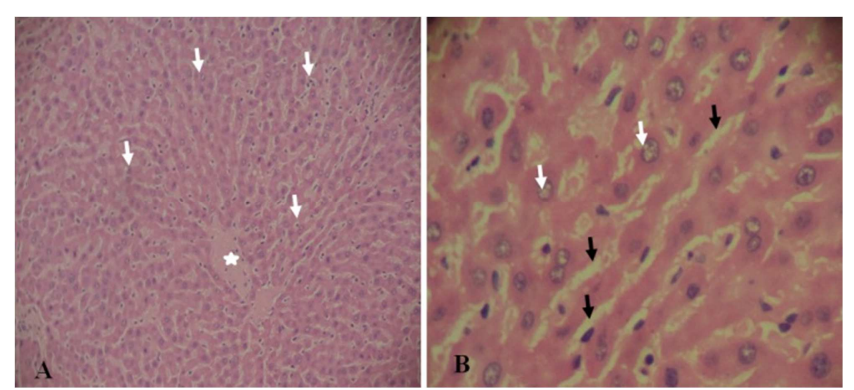

Figure 4. Liver induced + normal saline showing normal morphology. The hepatic cords present with clearly demarcated cells, with intact cytoplasmic components surrounding intact nuclei (white arrows). The hepatocytes are interspersed by hepatic sinusoids (Black arrows), White star=central vein. $H \& E$ A: X100 B: X400.
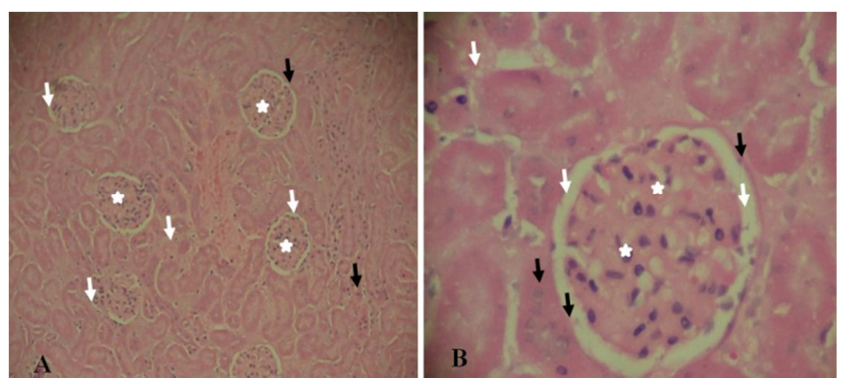

Figure 5. Kidney (Cortical area) of albino rat not induced + normal saline showing normal morphology, with clearly defined glomerular capsule (black arrows) surrounding the glomeruli (white arrows). The capsular space (white arrows) is clear and contains no substances. $H \& E$ A: X100 B: X400.
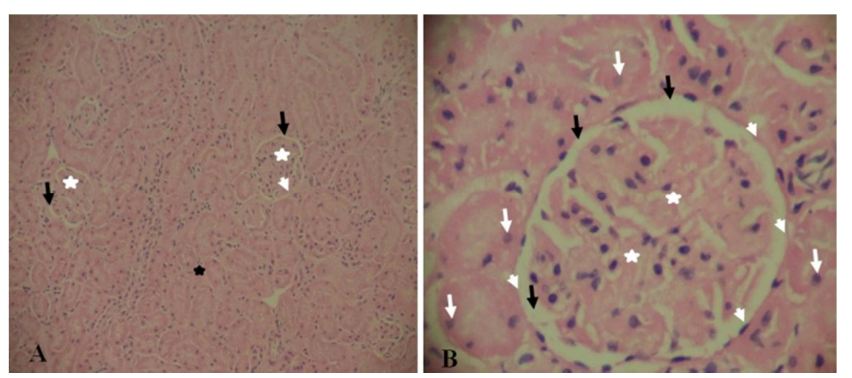

Figure 6. Kidney of albino rat induced + normal saline showing normal morphology. The glomerular capsules (white arrowheads) are clearly defined and give a demarcation between the capsular space (black arrows) and the kidney tubules. White stars=glomeruli, white arrows=nuclei of tubules. $H \& E$ A: X100 B: X400. 

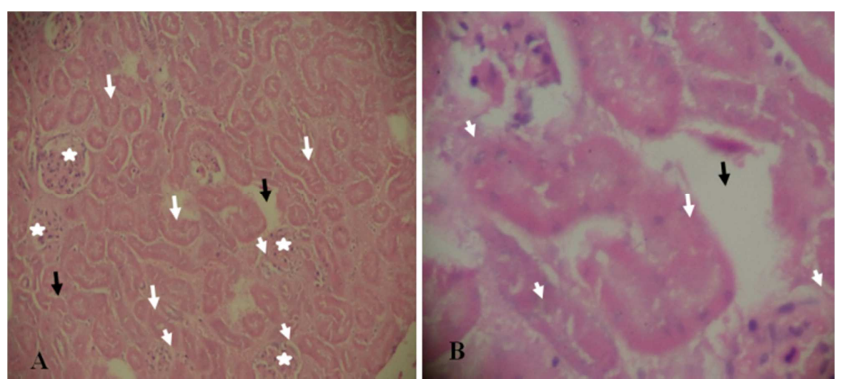

Figure 7. Kidney of Albino rat induced $+200 \mathrm{mg} / \mathrm{Kg}$ ethanolic root extract of M. scaber showing nuclear degeneration, evident by the loss of nuclei in the kidney tubules (white arrows) thereby presenting the tubules as a collection of cytoplasmic materials without nuclei. Glomerular hypertrophy is also evident by a great reduction in capsular spaces (white arrowheads). Black arrows=collecting tubules, white stars $=$ glomeruli. $H \& E$ A: X100 B: $X 400$.
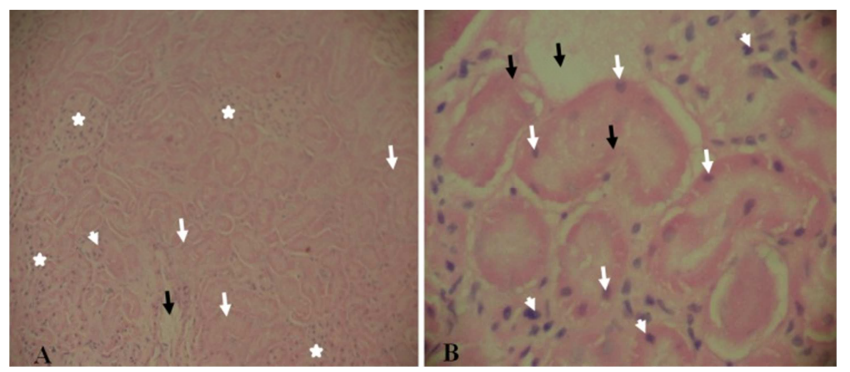

Figure 8. Kidney of Albino rat induced $+500 \mathrm{mg} / \mathrm{kg}$ aqueous root extract of mitracarpus scaber showing mild degeneration and inflammation. Most of the tubules present with completely lost nuclei while few present remnants of nuclei (white arrows). Mild inflammation is observed by the presence of inflammatory cells (white arrowheads) within the tissue. The glomeruli (white stars) present with hypertrophy thereby causing loss of capsular spaces. Black arrows $=$ collecting tubules. $H \& E$ A: X100 B:X400.
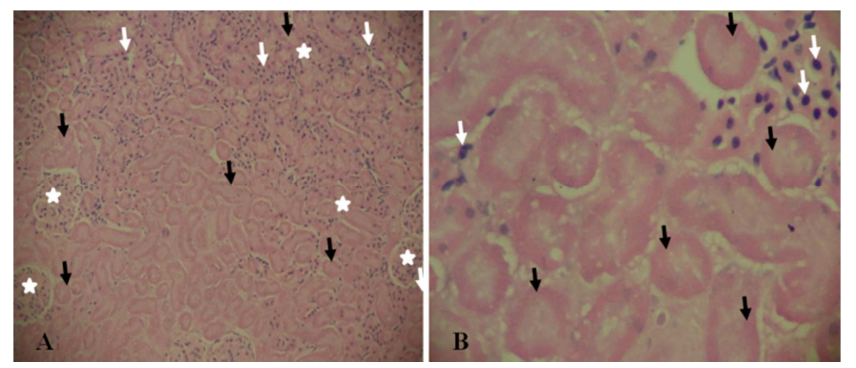

Figure 9. Kidney of Albino rat induced $+500 \mathrm{mg} / \mathrm{kg}$ ethanolic root extract of mitracarpus scaber, showing massive inflammation evident by the presence of inflammatory cells (white arrows) within the tissue. Tubular necrosis is shown by the appearance of kidney tubules (black arrows) with loss of nuclear material. $H \& E$ A: X100 B: X400.

\section{Discussion}

Paracetamol (PCM) is a common antipyretic agent that is safe in therapeutic doses but can produce fatal hepatic necrosis in man and experimental animals with toxic doses $[2,24]$. Paracetamol is metabolized primarily in the liver and eliminated by conjugation with sulfate and glucuronide, thereafter it is then excreted by the kidney. Nevertheless, paracetamol hepatotoxicity has been linked to the formation of toxic metabolites, when a part of it is activated by hepatic cytochrome $\mathrm{P}-450$ to a highly reactive metabolite $\mathrm{N}$-acetyl- p-benzoquinoneimine (NAPQI). Toxic metabolites (N-acetylp-benzoquineimine) can alkylate and oxidize intracellular $\mathrm{GSH}$, which results in liver GSH depletion subsequently leads to increased lipid peroxidation by abstracting hydrogen from a polyunsaturated fatty acid and ultimately, liver damage caused by higher doses of paracetamol. Due to liver damage, cellular leakage and loss of functional integrity result in elevated serum enzyme levels [24, 25].

The greatest amount of alanine transaminase (ALT) and aspartate transaminase (AST) are found in the liver followed by a lesser amount in the heart and in the skeletal muscles. When cells in these tissues are injured, these enzymes are released into the blood resulting in their increased serum levels. Since the liver contains the highest levels of both transaminases, any damage to the cells of the liver would result in elevated levels of (ALT and AST) in the serum. The degree of elevation is usually linked to the severity of the hepatocellular damage $[19,26]$, hence assessment of liver function can be carryout by quantifying these enzymes in the serum.

In the present study, paracetamol-induced acute hepatic damage as evidenced by a marked elevation in the levels of alanine aminotransferase (ALT), aspartate aminotransferase (AST) and alkaline phosphatase (ALP) as compared with the control group. The altered levels of these enzymes are in correspondence to the degree of liver damage induced by paracetamol. The increase in the levels of transaminases and alkaline phosphatase is a clear indication of cellular leakage and loss of functional integrity of the membrane resulting from liver injury [27, 28].

Treatment with the extract of Mitracarpus scaber roots altered the levels of these marker enzymes to near normal or only slightly elevated as compared with the control group, indicating a dose-dependent protection against liver damage. Pretreatment with $200 \mathrm{mg} / \mathrm{kg} \mathrm{b}$. w of the aqueous extract showed an increase in the liver enzymes levels this may be attributed to low concentration of phytonutrients like the flavonoids which have antioxidant properties that will help boost its protective effect, at $500 \mathrm{mg} / \mathrm{kg}$ of the ethanolic extract of Mitracarpus scaber roots an increase in the liver enzymes levels was observed, this might be due to the fact that alcohol (ethanol) can cause liver damage when ingested in higher quantity. Since $500 \mathrm{mg} / \mathrm{kg}$ is the highest dose of the ethanolic extract given, high concentration of the ethanol may be the reason behind the elevated levels of the liver enzymes. What that could be inferred from above is that the practice of boiling the roots in palm wine before ingestion may not give the desired hepato-protective result.

However, treatment with $500 \mathrm{mg} / \mathrm{kg}$ of the aqueous extract and $200 \mathrm{mg} / \mathrm{kg}$ of the ethanolic extract was found to significantly restore the PCM-induced alterations toward normalcy by decreasing the levels of AST and ALT except in ALP which shows slight increase. Hence, a reduction in the levels of these transaminases demonstrates membrane stabilizing activity of the extract and regeneration process of hepatocytes. This is in agreement with the commonly 
accepted view that serum levels of AST, ALT, and ALP return to normal with the healing of hepatic parenchyma and the regeneration of hepatocytes. The significant reduction in liver enzymes after treatment, suggests that the extract possesses hepatoprotective property [19, 28, 29]. High levels of AST indicate liver damage. In muscle, ALT catalyzes the conversion of alanine to pyruvate and glutamate and is released in similar manner. Therefore AST is more specific to liver and thus a better parameter for detecting liver damage $[19,28]$. In addition to that, High level of ALT in the serum has been shown to be a result of hepatocellular damage indicative of the fact the PCM has damaging effect on liver tissues.

The alterations in the levels of ALT and AST possibly occur due to the presence of flavonoids in the extracts used. Various phytoconstituents such as alkaloids, flavonoids and other phenolic constituents present in the plant extract could be responsible for the membrane-stabilizing activity. Histopathological findings on the kidney, showed that the administration of PCM at a higher dosage, poses no side effects to the kidney, however mild inflammation to the kidney was observed in the groups treated with the extracts of the plant, which indicates that the administration of the extract may have certain pharmacological effects to the functioning of the kidney.

\section{Conclusion}

Based on this study, it can be concluded that the hepatoprotective property of the roots extract of Mitracarpus scaber is dose-dependent and also dependent on the solvent used for the extraction. At $500 \mathrm{mg} / \mathrm{kg}$ of the aqueous extract and $200 \mathrm{mg} / \mathrm{kg}$ of the ethanolic extract of roots of Mitracarpus scaber has hepatoprotective action upon PCM induced hepatotoxicity in rats, which may be attributed to the presence of phytoconstituents such as alkaloids, flavonoids, glycosides, and other phytochemicals in the plant extract. However, the mechanism of hepatoprotection seems to involve the modulation of the antioxidant enzyme systems. These beneficial effects may be attributed to the individual or combined action of the phytoconstituents present in the extract. Therefore, it is pertinent to further determine, isolate and purify the exact bioactive constituents with the potential hepatoprotective property and also to identify the exact mechanism (s) of action and active phytoconstituent (s) involved in this effect for future studies. Studies can also be carried out to check the effect of the plant extract on other tissues of the body like the heart and spleen.

\section{References}

[1] F. Yan, Q. Y. Zhang, L. Jiao, T. Han, H. Zhang, L. P. Qin, R. Khalid, Synergistic hepatoprotective effect of Schisandrae lignans with Astragalus polysaccharides on chronic liver injury in rats, Phytomedicine, 16 (2009) 805-813.

[2] M. A. Dkhil, A. E. Abdel Moneim, T. A. Hafez, M. A.
Mubaraki, W. F. Mohamed, F. A. Thagfan, S. Al-Quraishy, Myristica fragrans kernels prevent paracetamol-induced hepatotoxicity by inducing anti-apoptotic genes and Nrf2/HO1 pathway, International journal of molecular sciences, 20 (2019) 993.

[3] C. P. Lee, P. H. Shih, C. L. Hsu, G. C. Yen, Hepatoprotection of tea seed oil (Camellia oleifera Abel.) against CCl4-induced oxidative damage in rats, Food and chemical toxicology, 45 (2007) 888-895.

[4] V. Mihailović, M. Mihailović, A. Uskoković, J. Arambašić, D. Mišić, V. Stanković, J. Katanić, M. Mladenović, S. Solujić, S. Matić, Hepatoprotective effects of Gentiana asclepiadea L. extracts against carbon tetrachloride induced liver injury in rats, Food and chemical toxicology, 52 (2013) 83-90.

[5] M. Mroueh, Y. Saab, R. Rizkallah, Hepatoprotective activity of Centaurium erythraea on acetaminophen-induced hepatotoxicity in rats, Phytotherapy Research: An International Journal Devoted to Pharmacological and Toxicological Evaluation of Natural Product Derivatives, 18 (2004) 431-433.

[6] M. Domenicali, P. Caraceni, F. Giannone, M. Baldassarre, G. Lucchetti, C. Quarta, C. Patti, L. Catani, C. Nanni, R. M. Lemoli, A novel model of CCl4-induced cirrhosis with ascites in the mouse, Journal of hepatology, 51 (2009) 991-999.

[7] E. Yoon, A. Babar, M. Choudhary, M. Kutner, N. Pyrsopoulos, Acetaminophen-induced hepatotoxicity: a comprehensive update, Journal of clinical and translational hepatology, 4 (2016) 131

[8] R. Tittarelli, M. Pellegrini, M. Scarpellini, E. Marinelli, V. Bruti, N. Di Luca, F. Busardo, S. Zaami, Hepatotoxicity of paracetamol and related fatalities, Eur Rev Med Pharmacol Sci, 21 (2017) 95-101.

[9] M. Gupta, U. K. Mazumder, T. S. Kumar, P. Gomathi, R. S. Kumar, Antioxidant and hepatoprotective effects of Bauhinia racemosa against paracetamol and carbon tetrachloride induced liver damage in rats, Iranian journal of Pharmacology and Therapeutics, 3 (2004) 12-10.

[10] A. Gilani, Q. Jabeen, M. Ghayur, K. Janbaz, M. Akhtar, Studies on the antihypertensive, antispasmodic, bronchodilator and hepatoprotective activities of the Carum copticum seed extract, Journal of Ethnopharmacology, 98 (2005) 127-135.

[11] R. R. Chattopadhyay, Possible mechanism of hepatoprotective activity of Azadirachta indica leaf extract: Part II, Journal of ethnopharmacology, 89 (2003) 217-219.

[12] A. Oyagbemi, A. Odetola, Hepatoprotective effects of ethanolic extract of Cnidoscolus aconitifolius on paracetamolinduced hepatic damage in rats, Pakistan Journal of Biological Sciences, 13 (2010) 164.

[13] N. Ncube, A. Afolayan, A. Okoh, Assessment techniques of antimicrobial properties of natural compounds of plant origin: current methods and future trends, African journal of biotechnology, 7 (2008).

[14] WHO, Traditional medicine: Fact sheet no. 134, December 2008, in, 2011.

[15] G. A. Cordell, M. D. Colvard, Some thoughts on the future of ethnopharmacology, Journal of ethnopharmacology, 100 (2005) 5-14. 
[16] G. Zirihi, A. Kra, D. Etien, Étude botanique et évaluation des activités antifongiques de Mitracarpus villosus (MV)(Rubiaceae) et Spermacoce verticillata (SV)(Rubiaceae) sur la croissance in vitro de Aspergillus fumigatus, Revue Méd. Pharm. Afr, 20 (2007) 9-17.

[17] W. Evans, Text Book: Trees and Evans Pharmacognosy, WB Sounders, in, Harcourt Publishers Ltd), London, 2002.

[18] G. Bisignano, R. Sanogo, A. Marino, R. Aquino, V. angelo, M. Germano, R. De Pasquale, C. Pizza, Antimicrobial activity of Mitracarpus scaber extract and isolated constituents, Letters in applied microbiology, 30 (2000) 105-108.

[19] B. Jonathan, M. Victor, K. M. Samuel, J. Sani, Some Hepatic Function indices in Trypanosoma brucei brucei-infected Rats treated with Aqueous Extract of Mitracarpus scaber, International journal of chemical and biological sciences, VOL. 1 (2015) 5.

[20] T. Abere, A. Onyekweli, G. Ukoh, In vitro antimicrobial activity of the extract of Mitracarpus scaber leaves formulated as syrup, Tropical Journal of Pharmaceutical Research, 6 (2007) 679-682.

[21] S. Reitman, S. Frankel, A colorimetric method for the determination of serum glutamic oxalacetic and glutamic pyruvic transaminases, American journal of clinical pathology, 28 (1957) 56-63.

[22] E. J. King, A. R. Armstrong, A convenient method for determining serum and bile phosphatase activity, Canadian Medical Association Journal, 31 (1934) 376.
[23] G. Avwioro, Histochemical uses of haematoxylina review, Jpcs, 1 (2011) 24-34.

[24] J. L. Wallace, Acetaminophen hepatotoxicity: NO to the rescue, British journal of pharmacology, 143 (2004) 1-2.

[25] S. R. Parmar, P. H. Vashrambhai, K. Kalia, Hepatoprotective activity of some plants extract against paracetamol induced hepatotoxicity in rats, J Herbal Med Toxicol, 4 (2010) 101106.

[26] N. K. Jain, A. K. Singhai, Protective effects of Phyllanthus acidus (L.) Skeels leaf extracts on acetaminophen and thioacetamide induced hepatic injuries in Wistar rats, Asian Pacific Journal of Tropical Medicine, 4 (2011) 470-474.

[27] B. Saraswat, P. Visen, G. Patnaik, B. Dhawan, Anticholestatic effect of picroliv, active hepatoprotective principle of Picrorhiza kurrooa, against carbon tetrachloride induced cholestasis, Indian journal of experimental biology, 31 (1993) 316-318.

[28] O. K. Shittu, U. Habibat, Y. Usman, Effect of methanolic leaf extract of Thymus vulgaris on some biomarker enzymes in Trypanosoma brucei infected rats, Int $\mathrm{J}$ pharm biomed Res, 4 (2013) 83-87.

[29] S. A. Sakr, S. Y. Shalaby, Ginger extract protects metalaxylinduced histomorphological and histochemical alterations in testes of albino mice, Journal of Applied Pharmaceutical Science, 1 (2011) 36. 